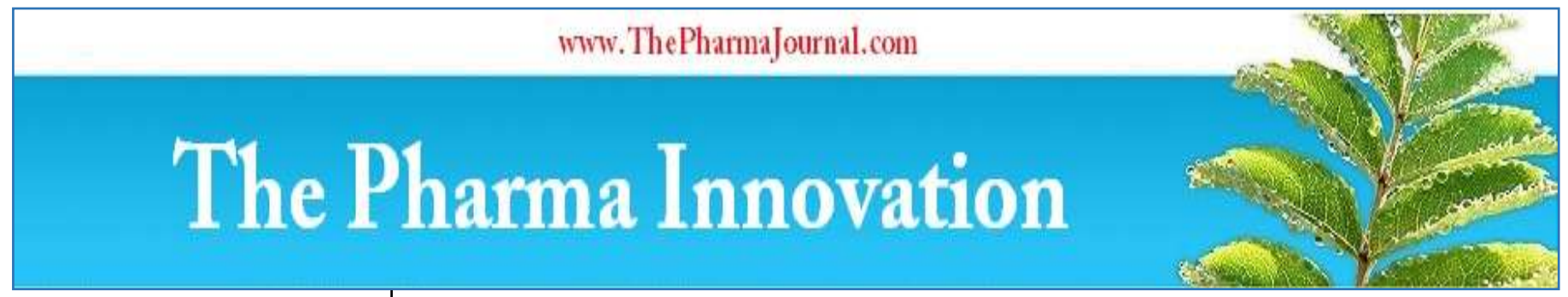

ISSN (E): 2277- 7695

ISSN (P): 2349-8242

NAAS Rating: $\mathbf{5 . 0 3}$

TPI 2021; 10(3): 313-319

(C) 2021 TPI

www.thepharmajournal.com

Received: 14-01-2021

Accepted: 18-02-2021

Singh N

College of Community Science, CAU, Tura, Meghalaya, India

Sangma B

College of Community Science, CAU, Tura, Meghalaya, India

Corresponding Author: Singh N

College of Community Science,

CAU, Tura, Meghalaya, India

\section{Diabetes mellitus: Status in North East India}

\section{Singh $\mathbf{N}$ and Sangma $B$}

DOI: $\underline{\text { https://doi.org/10.22271/tpi.2021.v10.i3e.5793 }}$

\section{Abstract}

Diabetes Mellitus is a common health problem across the globe. It is a lifestyle disease leading to Chronic Non Communicable Disease. India's prevalence to suffer from diabetes is next to China. Gradually diabetes can give impairment in the heart, blood vessels, eyes, kidneys and nerves. It is the considerable cause leading to premature mortality. Diabetes gives a large health burden across the globe. This research article explores diabetes mellitus in terms of current status of Diabetes Mellitus in North East India, strategies for prevention and management interventions of Diabetes Mellitus. Mean Lipid profile, FBS and anthropometric parameters of selected pre-diabetic subjects were also tested for significance at $5 \%$ level. Pre and post data were collected for both experimental and control group. The result showed that Body mass index and waist hip ratio were statistically significant at $5 \%$ level of significance. Biochemical parameters were also found to be significant at $5 \%$ level of significance.

Keywords: Diabetes Mellitus, North east, lipid profile, anthropometric measurements

\section{Introduction}

Diabetes mellitus is a metabolic disorder having multiple causation factors. It is signalised by chronic hyperglycemia accompanied by interference of carbohydrate, fat and protein metabolism. Diabetes is the condition in which the body either doesn't make enough insulin or unable to use insulin or both. A hormone called insulin is produce in an organ pancreas that lies near the stomach. Insulin aids glucose to get into the cells of our bodies (CDC).

Diabetes is a combination of heterogeneous disorders commonly presenting with episodes of hyperglycaemia and glucose intolerance (Sicree et al., 2006) ${ }^{[34]}$. The chronic hyperglycaemia of diabetes is accompanied by long-term impairment, abnormal functioning, and failure of different organs, particularly the eyes, kidneys, nerves, heart, and blood vessels (American Diabetes Association 2010) ${ }^{[37]}$.

Long-term complications of diabetes include retinopathy with potential loss of vision, nephropathy giving rise to renal failure; peripheral neuropathy with probable risk to foot ulcers, amputations, and Charcot joints; and autonomic neuropathy causing gastrointestinal, genitourinary, and cardiovascular symptoms and sexual dysfunction. Its symptoms include weight loss, blurry vision, frequent urination, increased thirst and hunger (Diabetes Care, 2009) ${ }^{[11]}$.

\section{Prevalence}

The prevalence of diabetes globally in 2019 is estimated to be $9.3 \%$ which is 463 million people, by 2030 it would be rising to 578 million i.e, $10.2 \%$ and $10.9 \%$ which is 700 million by 2045 . The prevalence is higher in urban (10.8\%) than rural $(7.2 \%)$ areas, and in highincome $(10.4 \%)$ than low-income countries $(4.0 \%)$ (International Diabetes Federation Diabetes, 2019) ${ }^{[29]}$.

The overall prevalence of diabetes in all 15 states of India was 7.3\% (95\% CI 7.0-7.5). The prevalence of diabetes varied from $4.3 \%$ in Bihar $(95 \%$ CI $3.7-5.0)$ to $10.0 \%(8.7-11.2)$ in Punjab and was higher in urban areas $(11 \cdot 2 \%, 10 \cdot 6-11 \cdot 8)$ than in rural areas $(5 \cdot 2 \%, 4 \cdot 9-5 \cdot 4$; $p<0.0001)$ and higher in mainland states $(8.3 \%, 7 \cdot 9-8.7)$ than in the northeast $(5 \cdot 9 \%, 5 \cdot 5-$

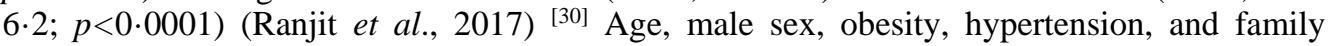
history of diabetes were independent risk factors for diabetes in both urban and rural areas Population based cross-sectional study was conducted in Nursing School in Yingkion in Upper Siang district of Arunachal Pradesh and diabetes mellitus was observed among $19.78 \%$ of the participants with additional $12.04 \%$ patients with impaired glucose tolerance (IGT). Diabetes mellitus was most prevalent among 50-59 years age group (32.10\%) (Jaman and Borang, 2014) ${ }^{[17]}$. 
Study was conducted among selected sub groups of the major tribal population comprising the Khasi and Jaintia community of the State of Meghalaya. The result from the random survey indicate that the average prevalence amongst the urban tribal Khasi and Jaintia population of the State was $9.89 \%$ and $12.5 \%$ respectively. Further, the prevalence was found to be higher for the age group above 40 years, constituting more than $80 \%$ of the total diabetic population (Syiem et al. 2012) [9]. According to NFHS-5 in West Garo Hills, Women who have high risk waist-to-hip ratio $(\geq 0.85)(\%)$ is $74.0 \%$ and Women who are overweight or obese (BMI $\geq 25.0 \mathrm{~kg} / \mathrm{m} 2)$ is $7.2 \%$. Blood sugar level - high or very high $(>140 \mathrm{mg} / \mathrm{dl})$ or taking medicine to control blood sugar level23 (\%) is $12.1 \%$ for women, Blood sugar level - high or very high $(>140$ $\mathrm{mg} / \mathrm{dl}$ ) or taking medicine to control blood sugar level is 24.7(\%) for men (NFHS-5).

A cross-sectional hospital-based study was conducted at Tura Civil Hospital, Meghalaya in the Out Patient Department (OPD) for Non-Communicable Disease (NCD) for a period of 2 months. A total of 100 outpatients were randomly selected and data were collected by interview method using a predesigned and pre structured questionnaire. The results showed that the prevalence of Diabetes was very high, with the incidence of Diabetes higher in the age group of fifty to sixty years $(44 \%)$, with more males $(64 \%)$ suffering from Diabetes than females (36\%). In comparison to the rural area, the urban area had a higher percentage (55\%) suffering from Diabetes. Non vegetarians $(88 \%)$ and patients who lived a sedentary lifestyle (73\%). (Marak, Momin \& Sharma, 2018) ${ }^{[28]}$.

\section{Strategies for Prevention and Management of Diabetes}

Strategies for prevention and management of diabetes would include implementing combined diet and physical activity promotion programs to prevent type 2 diabetes for people at increased risk. (Tuomileto J et al, 2001) ${ }^{[23]}$. Counseling, coaching, or a combination of both could be incorporated (ADCES, 2020 \& Ruey-Yu Chen et al) ${ }^{[31]}$.

- Engage community health workers in diabetes prevention programs to improve glycemic control and weight-related outcomes for people at increased risk for type 2 diabetes (ADA, 2015) ${ }^{[1]}$.

- Develop intensive lifestyle interventions for patients with type 2 diabetes to improve glycemic control and support dietary modification, regular physical activity, and weight management (ADA, 2017 \& Uusitupa, et al. 2019).

- Develop team-base care interventions to help patients manage type 2 diabetes and improve blood glucose, blood pressure, and lipid levels. Intensive lifestyle interventions: Dietary components may include tailored advice, and physical activity components may include structured and personalized guidance or supervised exercise training. Programs may have weight loss goals or include additional components related to weight loss or maintenance (ADA, Diabetes Care)

\section{Type 2 diabetes can often be prevented by}

- Eating smaller portions and healthy foods can help prevent or delay diabetes diagnoses (NIDDK, 2016) ${ }^{[12]}$

- Physical activity can help control blood glucose levels, weight, and blood pressure, as well as raise "good" cholesterol and lower "bad" cholesterol. (H. Kahleova)

- Losing just a small amount of weight (between 5 and 7 percent of total body weight) can prevent or delay type 2 diabetes for those who are at high risk for the disease
(Wilding, 2014) ${ }^{\text {[22] }}$

- Combined diet and physical activity promotion programs are effective in reducing new-onset diabetes. It also improve diabetes and cardiovascular disease risk factors, including overweight, high blood glucose, and high blood pressure. They are designed to prevent type 2 diabetes among people who are at increased risk for the disease. Diet and physical activity programs actively encourage people to improve their diet and increase their physical activity. (Balk et al, 2015) ${ }^{[16]}$.

- Team-based care is a health systems-level, organizational intervention that allots a multidisciplinary team to assist patients manages type 2 diabetes. Each team includes the patient, the patient's primary care provider, and health professionals. They assist patients for medical tests, use medications to manage risk factors, adhere to treatment, and make healthy behaviour and lifestyle alternatives (Community Guide, 2016) ${ }^{[13]}$.

- Interventions engaging community health workers for diabetes prevention improves blood sugar control and weight-related outcomes for people at risk for type 2 diabetes. Community health workers are frontline public health workers who serve as a bridge between underserved communities and healthcare systems. Programs may include education about diabetes prevention and lifestyle changes, or counselling for people at higher risk for diabetes (Community Guide, 2020) ${ }^{[14]}$.

- Intensive lifestyle interventions help type 2 diabetes patients improve glycemic control and reduce risk factors for cardiovascular disease. Patients with type 2 diabetes get counselling and support to change their diet or level of physical activity. Programs provide ongoing counselling, coaching, or individualized guidance on dietary modifications, regular exercise, or both. (Diabetes Care, 2017) ${ }^{[25]}$

\section{Management of Noninsulin-Dependent Diabetes Mellitus}

Basic principles

- Precise diagnosis is crucial. Therefore priority should be on using appropriate diagnostic criteria.

- Treatment should also consider on the correction of any related CVD risk factors such as smoking, hyperlipidemias, and obesity and keeping track of blood pressure and treatment of hypertension.

- Personal care is crucial. Knowledge about diabetes is the base for management of diabetes. In lack of education the desired therapy targets will be difficult to achieve. Active participation of the patient is to be encourage and enabled in managing and monitoring the condition.

- Good control is essential. Self-monitoring enhance the quality and safety of therapy.

- The health care system should ensure that people with diabetes have access to the basic requirements essential to practise self-care.

- Record-keeping is important and a basic requirement for the management and follow-up of diabetes patient. (WHO, Management of Diabetes Mellitus, 1994)

\section{General objectives of diabetes management}

- To relieve symptoms

- To correct associated health problems and to reduce morbidity and mortality

- To prevent possible acute and long-term complications 
and to provide timely intervention

- To improve the quality of life and productivity of the individual with diabetes (WHO, Management of Diabetes Mellitus, 1994)

\section{Basic educational requirements}

The person with diabetes should acquire adequate knowledge and skills in the following:

- individual therapy targets

- individual nutritional requirements and meal planning

- type and extent of exercise and physical activity

- Interaction of food intake and physical activity with oral hypoglycaemic drugs/insulin

- Improvements in lifestyle, for example harmful effects of smoking, obesity and alcohol intake (Uusitupa et al, 2019)

- Self-monitoring and significance of results and actions to be taken

- how to cope with emergencies (illness, hypoglycaemia)

- how to avoid complications and detect them at an early stage, e.g. how to take care of the feet. (WHO, Management of Diabetes Mellitus,1994)

\section{Dietary treatment should aim at}

- ensuring weight control, providing nutritional requirements

- allowing good glycaemic control with blood glucose levels as close to normal as possible

- correcting any associated blood lipid abnormalities

- ensuring consistency and compatibility with other forms of treatment if used, for example oral agents or insulin. (WHO, Management of Diabetes Mellitus,1994)

- The following principles are recommended as dietary guidelines for people with diabetes:

- Dietary fat should provide $25-35 \%$ of total intake of calories but saturated fat intake should not exceed $10 \%$ of total energy. Cholesterol consumption should be restricted and limited to $300 \mathrm{mg}$ or less daily.

- Protein intake can range between 10-15\% total energy $(0.8-1 \mathrm{~g} / \mathrm{kg}$ of desirable body weight). (Gosby et.al, 2011) ${ }^{[19]}$ Requirements increase for children and during pregnancy. Protein from both animal and vegetable sources should be derived. Carbohydrates provide 50$60 \%$ of total caloric content of the diet. Although it has been traditionally recommended that carbohydrates should be complex and high in fibre, more emphasis should be placed on the total amount of carbohydrates consumed than the source of carbohydrate.

- Excessive salt intake is to be avoided. It should be particularly restricted in people with hypertension and those with nephropathy (Horikawa and sone, 2017).

- Artificial sweeteners sorbital and fructose are to be used in moderation as it has a potential detrimental impact on body weight, insulin sensitivity, and blood lipids. (Johnson et al., 2009; Stanhope et al., 2009)

- The same precautions regarding alcohol intake that apply to the non diabetic population also apply to people with diabetes. Additionally, however, alcohol tends to increase the risk of hypoglycemia in those taking antidiabetic drugs and should be particularly avoided in those with lipid abnormalities and patients with neuropathy.

- Except in special conditions like pregnancy and lactation, routine vitamin and mineral supplementation is generally not needed in people with a well balanced diet. There is, at present, no definite evidence to confirm that such treatment has any benefits. (WHO, Management of Diabetes Mellitus,1994)

\section{Meal planning}

- Assessment of dietary intake and individual needs of those with diabetes should be made as part of the initial management. Under optimal circumstances, this task is the responsibility of an experienced dietician, in consultation with the treating physician. However, after appropriate training the physician and the nurse can take on this responsibility in places where dietitians are not available. Meals and food intake should be planned in relation to economic factors and local circumstances concerning availability and cultural and social values. Special consideration should be given to meal planning during the month of Ramadan.

- Meals should be evenly distributed throughout the day. Consistency of food timing and energy intake from day to day should be emphasized, especially by those taking insulin. Exercise Physical activity promotes weight reduction and improves insulin sensitivity, thus lowering blood glucose levels. Together with dietary treatment, a programme of regular physical activity and exercise should be considered for each person. Such a programme must be tailored to the individual's health status and fitness. People should, however, be educated about the potential risk of hypoglycaemia and how to avoid it. (Russell et al., 2016 \& WHO, Management of Diabetes Mellitus, 1994) ${ }^{[26]}$.

\section{Management of Insulin-Dependent Diabetes Mellitus (IDDM)}

\section{Emphasis should be placed on}

- empowering the person with diabetes to take an active part in the management and monitoring of his/her condition;

- ensuring accessibility to the minimum standards of diabetes care, especially insulin and facilities for self-care and observation

- providing adequate education of the person with diabetes and family concerning all aspects of management

- developing an organized system of health care and regular follow-up with recordkeeping in all cases

- providing adequate time for the health care consultation and easy and immediate access to medical advice in emergency situations; and

- ensuring regular review of self-management skills, particularly those required for insulin injection; regular enquiry on the occurrence of potential side effects of therapy and inspection of injection sites for local complications. (WHO, Management of Diabetes Mellitus, 1994) ${ }^{[26]}$.

\section{Dietary therapy}

Dietary therapy should be directed to match food intake with insulin therapy to keep away from uncontrolled swings in blood glucose levels and avoid hypoglycaemia. (Russell et al., 2016, WHO, Management of Diabetes Mellitus, 1994) ${ }^{[26]}$.

Meal planning should receive adequate emphasis in IDDM

- Food intake to meet the requirements for normal growth and development.

- Calories to be distributed into main meals and regular 
snacks, taking into consideration local circumstances and the type of insulin therapy. It can be of three main meals with snacks in between and at bedtime, frequency and energy content of the snacks depends on the treatment and calorie requirements.

- People with diabetes needs to trained to adjust their calorie intake and insulin according to self-monitoring results and adjust it with physical exercise. Additional carbohydrate intake is required to prevent hypoglycaemia which may result from prolonged or unaccustomed physical activity (WHO, Management of Diabetes Mellitus, 1994) ${ }^{[26] .}$

\section{Materials and Methods}

Pre diabetic subjects of statistically significant number were selected randomly for both experimental and control group. Criteria for excluding the subjects were hypothyroidism or hyperthyroidism, renal, cardiac or GIT disturbance.

Written consent was taken from the subjects prior to conduct the study. Institutional Ethical clearance was also taken for project work. Feeding trial was done with developed mixes for three months. Pre post assessment was done for anthropometric and biochemical parameters of the selected subjects.

Table 1: Mean and SD Table for Lipid profile, FBS and anthropometric parameters of selected pre-diabetic subjects

\begin{tabular}{|c|c|c|c|c|c|c|}
\hline \multirow{3}{*}{ Parameter } & \multicolumn{2}{|c|}{ Experimental $(n=30)$} & \multirow[b]{2}{*}{ T value } & \multicolumn{3}{|c|}{ Control $(n=30)$} \\
\hline & Pre & post & & Pre & post & T value \\
\hline & Mean/SD & Mean/SD & & Mean/SD & Mean/SD & \\
\hline Total Cholesterol (mg/dl) & $165.97 / 16.87$ & $159.70 / 16.96$ & $6.20 \mathrm{~ns}$ & $110.80 / 12.79$ & $109.30 / 12.66$ & 0.01 \\
\hline Triglycerides (mg/dl) & $88.63 / 12.91$ & $85.10 / 12.14$ & $2.41 \mathrm{~ns}$ & $78.97 / 6.65$ & $79.13 / 7.00$ & 0.46 \\
\hline High Density Lipoprotein (mg/dl) & $49.87 / 4.19$ & $49.67 / 4.01$ & $0.08 *$ & $48.73 / 3.93$ & $49.87 / 4.29$ & 0.01 \\
\hline Low Density Lipoprotein $(\mathrm{mg} / \mathrm{dl})$ & $98.37 / 18.53$ & $98.37 / 18.53$ & $0.5^{*}$ & $46.27 / 13.79$ & $46.32 / 13.72$ & 0.20 \\
\hline Very Low-Density Lipoprotein (mg/dl) & $17.73 / 2.58$ & $17.02 / / 2.43$ & $0.27 *$ & $15.79 / 1.33$ & $15.79 / 1.33$ & 1 \\
\hline Total Cholesterol/High Density Lipoprotein & $3.11 / 0.55$ & $3.25 / 0.51$ & $0.33 *$ & $2.29 / 0.33$ & $2.21 / 0.33$ & 0.34 \\
\hline Low Density Lipoprotein/High Density Lipoprotein & $2.00 / 0.49$ & $2.01 / 0.49$ & $0.95 *$ & $0.96 / 0.32$ & $0.94 / 0.31$ & 0.80 \\
\hline Random BloodSugar (mg / dl) & $98.33 / 8.25$ & $95.90 / 8.63$ & $0.26^{*}$ & $99.33 / 10.50$ & $99.33 / 10.50$ & 1 \\
\hline HbA1C Glycated haemoglobin & $5.96 / 0.24$ & $5.76 / 0.24$ & $1.64 *$ & $6.03 / 0.24$ & $6.04 / 0.23$ & 0.57 \\
\hline Heamoglobin & $11.15 / 0.88$ & $11.44 / 0.88$ & 0.20 & $11.44 / 0.77$ & $11.44 / 0.77$ & 1 \\
\hline Height $(\mathrm{m})$ & $1.55 / 0.05$ & - & 1 & $1.56 / 0.04$ & & 1 \\
\hline Weight $(\mathrm{kg})$ & $58.22 / 4.07$ & $57.00 / 3.87$ & $4.06 \mathrm{~ns}$ & $53.07 / 4.40$ & $53.23 / 4.26$ & 0.25 \\
\hline Body Mass Index & $24.13 / 0.82$ & $23.62 / 0.75$ & $1.35^{*}$ & $21.91 / 1.56$ & $21.98 / 1.46$ & 0.28 \\
\hline Waist Circumference $(\mathrm{cm})$ & $79.30 / 6.32$ & $77.70 / 6.47$ & $2.64 \mathrm{~ns}$ & $75.30 / 6.32$ & $75.27 / 6.29$ & 0.32 \\
\hline Hip Circumference $(\mathrm{cm})$ & $97.67 / 8.46$ & $97.70 / 8.48$ & $0.98^{*}$ & $94.67 / 8.46$ & $94.67 / 8.46$ & 1 \\
\hline Waist Hip Ratio & $0.81 / 0.03$ & $0.80 / 0.02$ & $0.01 *$ & $0.80 / 0.03$ & $0.80 / 0.03$ & 0.95 \\
\hline
\end{tabular}

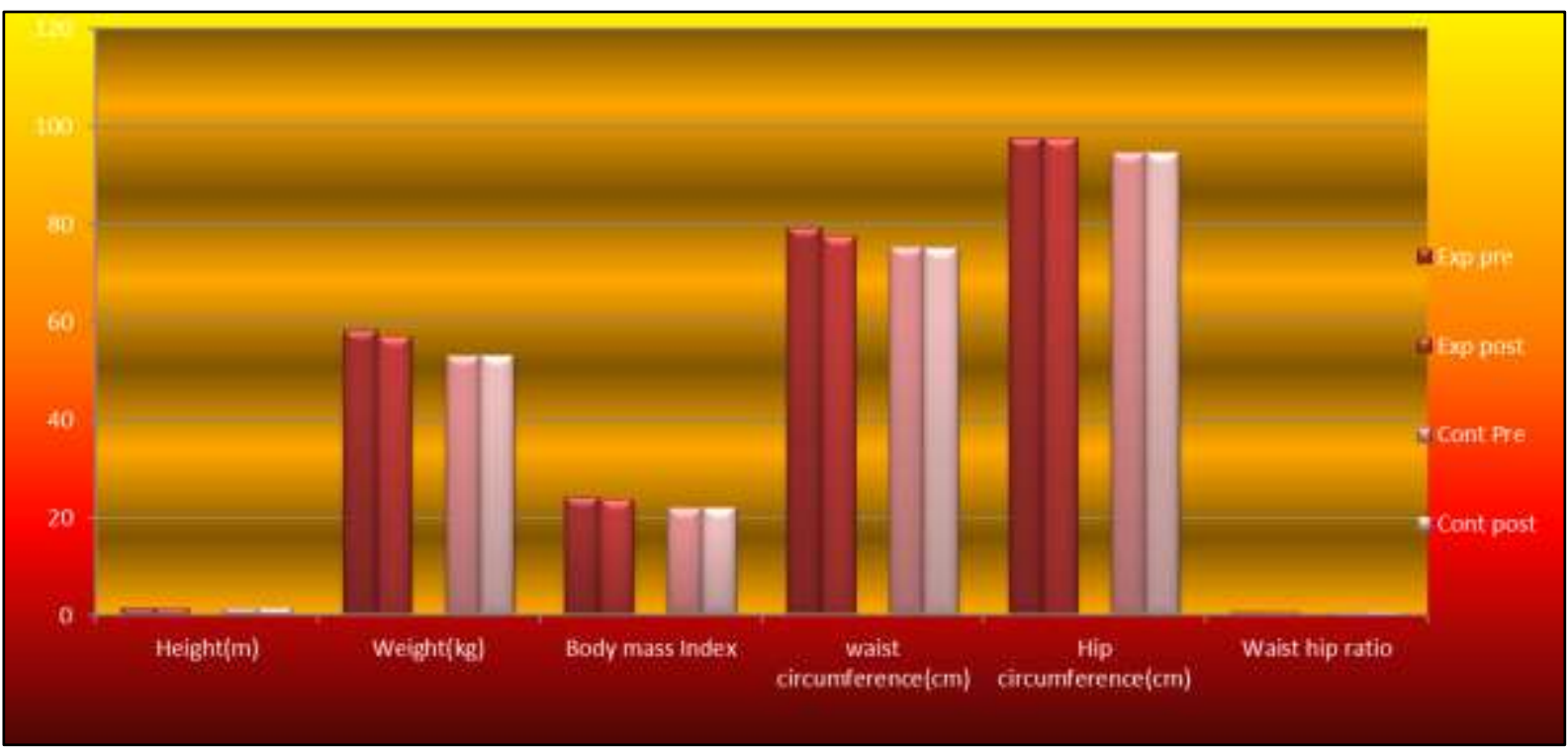

Fig 1: Anthropometric parameters of selected experimental and control pre-diabetic subjects shown as bar diagram. 


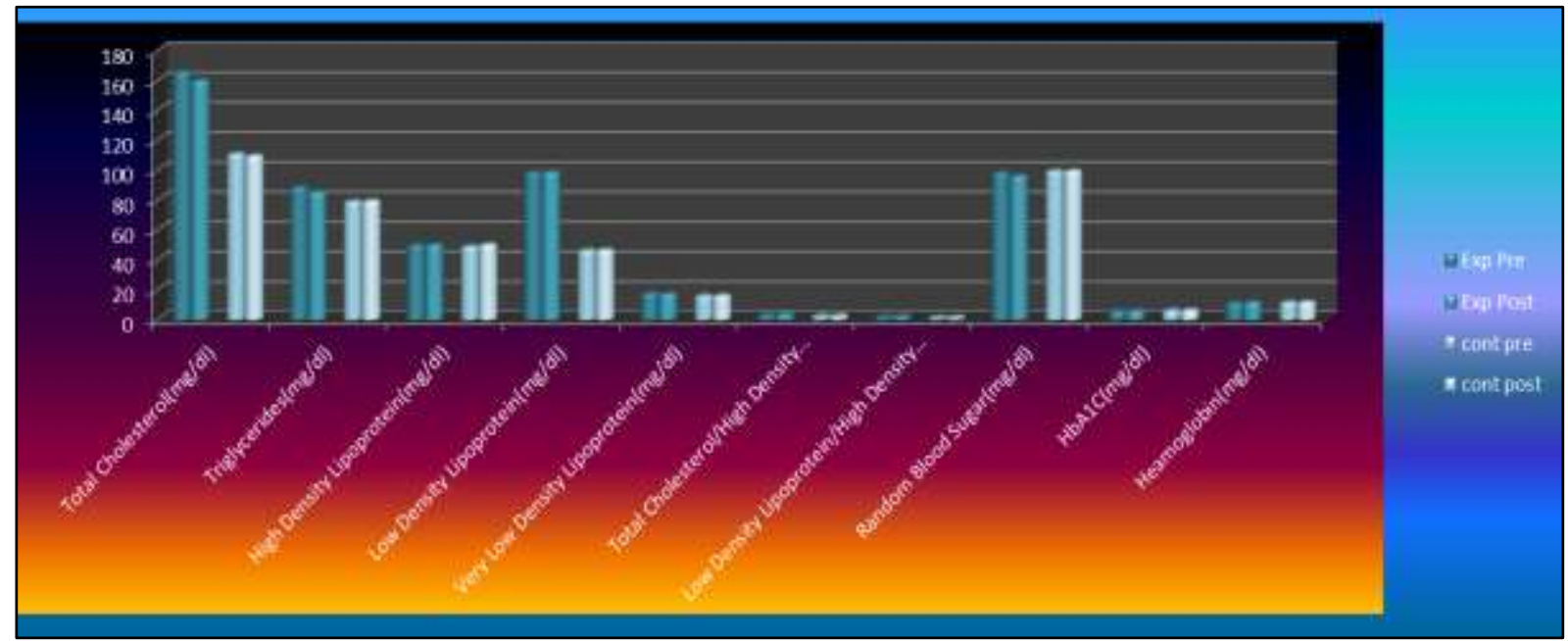

Fig 2: Lipid profile, RBS, Heamoglobin and HbA1C of selected experimental and control pre-diabetic subjects shown as bar diag

\section{Discussion}

In this study 60 pre diabetic subjects were evaluated. Mean $\mathrm{HbA} 1 \mathrm{C}$ was $5.96 \mathrm{~g} / \mathrm{dl}$ in experimental group and $6.03 \mathrm{~g} / \mathrm{dl}$ in control group. According to American Diabetes Association, $2011 \& 2014^{[2,3]}$, HbA1c range of non diabetes falls between $4.0 \%-5.6 \%$. While the pre-diabetes usually has HbA1c levels as $5.7 \%-6.4 \%$, and those with $6.4 \%$ or higher HbA1c levels have diabetes.

Several previous studies have observed that BMI, waist circumference was a good predictor of pre-diabetes (Pandey U.et al. 2017, and Vineetha K. et al.,2018) ${ }^{[38,40]}$. Results in this study however have shown that BMI were in somehow nearer to normal range in Pre-Diabetes i.e. mean BMI 24.13 in experimental group and 21.91 mean BMI in control group at Pre-test. Similarly in other studies too, it has indicated that Asian subjects are at risk to diabetes and cardiovascular diseases even at lower levels of BMI when compared with the white population (Mckeigue PM et al. 1991 and Enas. E.A. et $a l, 1992)^{[21,15]}$. This can be attributed to body fat distribution; Asian Indians tend to have more visceral adipose tissue, causing higher insulin resistance, despite having lean BMI (Chandalia M et al.,1999 and Banerji, 1999.) ${ }^{[7,4]}$.

In this study it was found that triglyceride (TG) levels were normal i.e. mean TG value $88.63 \mathrm{mg} / \mathrm{dl}$ for experimental and mean $78.97 \mathrm{~g} / \mathrm{dl}$ for control in pre test and after feeding trials mean TG value was reduced to $85.10 \mathrm{~g} / \mathrm{dl}$ in experimental group. HDL mean value in experimental group was $49.87 \mathrm{~g} / \mathrm{dl}$ and $48.73 \mathrm{~g} / \mathrm{dl}$ in control group at Pre-test. During Post test, after feeding trials mean HDL value was reduced to $49.67 \mathrm{~g} / \mathrm{dl}$ in experimental group.

According to study conducted by Vineetha K.et al.,2018 [40], waist circumference was one of the most predictive measure. However, contrary to this finding as all subjects of this study was farm women of hilly region mean waist circumference and mean waist hip ratio is falling in normal category i.e. 79.30 and 0.81 respectively. Waist hip ratio has weakest correlation as in study done by Jerzy, 2003 and waist circumference showed strongest correlation. Another study conducted by Silke et.al, $2010{ }^{[35]}$ there was positive association between waist circumference and risk of diabetes in persons with lower BMI. Findings of this study can be justified on the basis of their food consumption pattern. A study conducted by IIPS University in Mumbai reported that Natives of Indian states where a non-vegetarian diet is common are more likely to be living with diabetes. A $74 \%$ state level correlation between diabetes prevalence and consumption of meat, fish and eggs was reported. In another published peer reviewed Kerela and West Bengal were the states with the highest calorie consumption of non-vegetarian food groups found higher prevalence of diabetes (Quartz India, 2019) ${ }^{[42]}$.

In this study the difference between mean pre and post intervention in experimental group was found significant for Body mass index, waist hip ratio, High Density Lipoprotein Low Density Lipo protein, Very Low-Density Lipoprotein, Random Blood sugar and HbA1C Glycated haemoglobin at 5 percent level of significance.

\section{Conclusion}

Diabetes mellitus is a growing health problem in the world that causes severe morbidity and mortality. The above review has given the information about diabetes, its prevalence, strategies for prevention and management. High fibre mixes have shown positive impact on health management.

Acknowledgement: The authors are thankful to All India Coordinated Research Project for funding the study.

\section{References}

1. American Diabetes Association. Facts about type 2 2015. http://www.diabetes.org/diabetes-basics/type2/facts-about-type-2.html?loc=db-slabnav

2. American Diabetes Association (ADA) Diagnosis and classification of diabetes mellitus. Diabetes Care 2011;34:S62-9.

3. American Diabetes Association (ADA) Standards of medical care in diabetes. Diabetes Care 2014;37:S14-80.

4. Banerji MA, Faridi N, Atluri R, Chaiken RL, Lebovitz HE. Body composition, visceral fat, leptin and insulin resistance in Asian Indian men. $J$ Clin Endocrinol Metab 1999;84:137-144.

5. Centers for Disease Control and Prevention Diabetes 2016. https://www.cdc.gov/chronicdisease/resources/publ ications/aag/diabetes.html

6. Chamukuttan Snehalatha, Vijay Viswanathan, Ambady Ramachandran. Cutoff Values for Normal Anthropometric Variables in Asian Indian Adults 2016.

7. Chandalia M, Abate N, Garg A, Stray-Gundersen J, Grundy SM. Relationship between generalized and upper body obesity to insulin resistance in Asian Indian men. J Clin Endocrinol Metab 1999;84:2329-2335.

8. Chika Horikawa, Hirohito Sone. Dietary salt intake and 
diabetes complications in patients with diabetes: An overview, Journal of Gen Fam Med 2017;18(1):16-20.

9. Syiem D, Yngdoh WL, Warji P, Tariang D, Dkhar A, Deingdoh AMR. Prevalence of diabetes amongst the Khasi and Jaintia population of Meghalaya, The NEHU Journal 2012;10:1.

10. Diabetes Care $2003 ; 26(5): 1380-1384$. https://doi.org/10.2337/diacare.26.5.1380

11. Diabetes Care, Diagnosis and classification of Diabetes Mellitus, American Diabetes Association 2009;32(Suppl 1):S62-S67.

12. Diabetes Diet, Eating, \& Physical Activity, National Institute of Diabetes and Digestive and Kidney Diseases (NIDDK) 2016.

13. Diabetes Management: Team-Based Care for Patients with Type 2 Diabetes, The Community Guide 2016. https://www.thecommunityguide.org/findings/diabetesmanagement-team-based-care-patients-type-2-diabetes

14. Diabetes Prevention: Interventions Engaging Community Health Workers. The Community Guide 2020.

15. Enas EA, Yusuf S, Mehta JL. Prevalence of coronary artery disease in Asian Indians. Am J Cardiol 1992;70:945-949

16. Ethan M Balk, Amy Earley, Gowri Raman, Esther A Avendano, Anastassios G Pittas, Patrick L Remington. Combined Diet and Physical Activity Promotion Programs to Prevent Type 2 Diabetes Among People at Increased Risk: A Systematic Review for the Community Preventive Services Task Force, Intern Med 2015;163(6):437-451.

17. Forhad Akhtar Zaman and Anita Borang, Prevalence of diabetes mellitus amongst rural hilly population of North Eastern India and its relationship with associated risk factors and related co-morbidities, J Nat Sci Biol Med 2014;5(2):383-388.

18. Global burden of diabetes. International Diabetes federation. Diabetic atlas fifth edition, Brussels 2011. Available at http://www.idf.org/diabetesatlas

19. Gosby AK, Conigrave AD, Lau NS, Iglesias MA, Hall $\mathrm{RM}$, Jebb SA, et al. Testing protein leverage in lean humans: A randomised controlled experimental study. PLoS One 2011;6:e25929.

20. https://www.thecommunityguide.org/findings/diabetesintensive-lifestyle-interventions-

patientstype2diabetes\#: :text=Intensive $\% 20$ lifestyle $\% 20 \mathrm{i}$ nterventions \%20provide \%20ongoing,of\%20six \%20mont hs\%20or\%20longer., retrieved on 13/09/20

21. https://www.thecommunityguide.org/sites/default/files/as sets/What-Works-Factsheet-Diabetes.pdf, retrieved on $13 / 09 / 20$

22. Wilding JPH. The importance of weight management in type 2 diabetes mellitus, Int J Clin Pract 2014;68(6):682691.

23. Jaakko Tuomilehto, Jaana Lindström, Johan G. Eriksson, Timo T. Valle, Helena Hämäläinen et al. Prevention of Type 2 Diabetes Mellitus by Changes in Lifestyle among subjects with impaired glucose Tolerance. The New England Journal of Medicine 2001;344(18)344:13431350

24. Jerzy Lopatynski, Grazyna Mardarowicz, Grzegorz Szczesniak, A Comparative evaluation of waist circumference, waist-to-hip ratio, waist-to-height ratio and body mass index as indicators of impaired glucose tolerance and as risk factors for type- 2 diabetes mellitus,
Ann Univ Mariae Curie Skloddowska Med, 2003;58(1):413-9.

25. Lifestyle Management, American Diabetes Association, Diabetes Care 2017;40(Supplement 1):S33-S43.

26. Management of Diabetes Mellitus Standards of Care, World Health Organization 1994. https://applications.emro.who.int/dsaf/dsa509.pdf?ua=1, retrieved on $15 / 09 / 20$

27. Mckeigue PM, Shah B, Marmott MG: Relationship of central obesity and insulin resistance with high diabetes prevalence and cardiovascular risk in South Asians. Lancet 1991;337:382-386.

28. Natasha Marak D, Alina Ch. Momin, Leebeliya Sharma G. Incidence and Knowledge of Diabetes Mellitus of the Residents of Tura Town: A Case Study, Int. J. Curr. Microbiol. App. Sci 2018;7(9):1756-1763.

29. Pouya Saeedi, Inga Petersohn, Paraskevi Salpea, Dominic Bright, Rhys Williams, et al. Global and regional diabetes prevalence estimates for 2019 and projections for 2030 and 2045: Results from the International Diabetes Federation Diabetes Atlas, $9^{\text {th }}$ edition 2019;157:107843.

30. Ranjit Mohan Anjana, Mohan Deepa, Rajendra Pradeepa, Jagadish Mahanta, Kanwar Narain, Hiranya Kumar Das, et al. Prevalence of diabetes and prediabetes in 15 states of India: results from the ICMR-INDIAB populationbased cross sectional-study, Published 2017, 07. DOI: https://doi.org/10.1016/S2213-8587(17)30174-2.

31. Ruey-Yu Chen, Li-Chi Huang, Chien-Tien Su, YaoTsung Chang, Chia-Lin Chu, Chiao-Ling Chang, et al . Effectiveness of Short-Term Health Coaching on Diabetes Control and Self-Management Efficacy: A Quasi-Experimental Trial,

32. Dr Wacker S. Suite, Chicago, Association of Diabetes Care and Education Specialists. 2020

33. Sheri R Colberg, Ronald J Sigal, Bo Fernhall, Judith G Regensteiner, Bryan J Blissmer, Richard R Rubin, et al. Albright and Barry Braun, Exercise and Type 2 Diabetes, Diabetes Care 2010;33(12):e147-e167.

34. Sicree R, Shaw J, Zimmet P. The Global Burden. Diabetes and Impaired Glucose Tolerance. Prevalence and Projections. In: Gan, D. ed. Diabetes Atlas, 3rd edn. Brussels: International Diabetes Federation, pp. 16-103

35. Silke Feller, Heiner, Boeing and Tobias Pischon, Body mass index, waist circumference, and the risk of type 2 diabetes mellitus: implications for routine clinical practice. Dtsch Arztebl Int 2010;107(26):470-6.

36. Simple Steps to Preventing Diabetes. The Nutrition Source 2021.

37. Standards of Medical Care in Diabetes, American Diabetes Association, Diabetes Care 2010;33(Supplement 1):S11-S61.

38. Sue L Lau, Rati Debarma, Thomas N, Asha HS, Vasan KS, RG Alex, et al. Healthcare Planning in North-East India: A Survey on Diabetes Awareness, Risk Factors and Health Attitudes in a Rural Community.

39. Umeshwar Pandey, Tanu Midha, Pravin Katiyar, Pranay Wal, Samarjeet Kaur, Dinesh Singh Martolia. Anthropometric indicators as predictor of Pre-diabetes in Indian adolescents. Indian Heart Journal 2017;69(4):474479.

40. Vineetha K, Ramdas Nayak, Kirtana Raghurama Nayak, Sudha Vidyasagar, Asha Kamath. Body composition analysis, anthropometric indices and lipid profile markers 
as predictors for prediabetes. PLoS ONE 2018;13(8):e0200775. https://doi.org/10.1371/journal. pone. 0200775

41. Wendy R Russell, Athanasia Baka, Inger Björck, Nathalie Delzenne, Dan Gao, Helen R Griffiths, et al. Impact of Diet Composition on Blood Glucose Regulation, Critical Reviews in Food Science and Nutrition 2016;56:4:541-590.

42. Kuwar Singh. Data show higher Diabetes prevalence in meat-loving Indian States. Quartz India, 2019. https://qz.com/india/1673186/diabetes-more-common-inindias-meat-loving-kerala-west bengal/\#: :text=Conversely $\% 2 \mathrm{C} \% 20 \% \mathrm{E} 2 \% 80 \% 9 \mathrm{CKeral}$ a\%20and $\% 20$ West $\% 20$ Bengal,reviewed $\% 20$ Journal $\% 20$ of $\% 20$ Public $\% 20$ Health. Accessed on 24/02/2021 